\title{
TNF gene deletion prevents lipopolysaccharide- mediated sensitisation of the neonatal mouse brain to hypoxic-ischaemic insult
}

\author{
A Sahota*, G Kendall, S Lange, G Raivich \\ From International Conference for Healthcare and Medical Students 2011 \\ Dublin, Ireland. 4-5 November 2011
}

\section{Introduction}

An increasing body of evidence suggests a synergistic link between infection/inflammation and hypoxia-ischaemia in the pathogenesis of perinatal brain injury. Deletion of the TNF cytokine gene cluster (TNF, LT $\alpha$ and LT $\beta$ ) has previously been shown to abolish lipopolysaccharide (LPS)-mediated sensitisation of the developing brain to hypoxic-ischaemic (HI) insult. In this study, I investigated if single TNF and LT $\beta$ gene deletions prevented LPSsensitised $\mathrm{HI}$ brain injury.

\section{Methods}

Postnatal day 7 mice homozygous for either TNF or LT $\beta$ cytokine gene deletions received either $0.3 \mathrm{mcg} / \mathrm{g}$ LPS or saline by intraperitoneal injection 12 hours prior to 30-minute $\mathrm{HI}$ insult. Coronal forebrain sections were examined for brain injury using Nissl stain and microglial activation using the activation marker $\alpha \mathrm{M} \beta 2$ intergrin $(\alpha M)$. Injury was scored in ipsilateral grey matter regions and external capsule white matter (ipsilateral and contralateral). Values given are mean \pm SEM and data was analysed for significant differences using unpaired two-tailed Student's t-test.

\section{Results}

Pre-treatment with LPS in wild-type mice $(\mathrm{n}=13)$ resulted in significantly increased overall brain injury $(0.96 \pm 0.17 \mathrm{v}$ $3.11 \pm 0.44, \mathrm{p}<0.05)$ and $\alpha \mathrm{M}$ expression across all assessed ipsilateral forebrain regions $(\mathrm{p}<0.05)$ compared to saline pre-treated controls $(n=13)$. TNF knockout animals pretreated with LPS $(\mathrm{n}=14)$ did not show a significant difference in overall brain injury $(2.82 \pm 0.50 \mathrm{v} 2.90 \pm 0.57$, $\mathrm{p}=0.91)$ or regional $\alpha \mathrm{M}$ expression compared to saline controls $(n=13)$. Wild-type animals from the LT $\beta$ breeding group did not exhibit increased overall brain injury in response to LPS pre-treatment $(n=4)$ compared to saline controls $(n=4)$.

\section{Conclusions}

Deletion of the TNF cytokine gene prevents lipopolysaccharide-mediated sensitisation of the neonatal brain to hypoxic-ischaemic insult. Sensitisation to LPS was not seen in the wild-type animals in the LT $\beta$ strain, which could suggest possible spontaneous mutation of the gene (s) responsible for LPS response in the strain used. Future work into the effects of LT $\alpha$ and LT $\beta$ gene deletions, cellspecific gene deletions and pharmacological inhibition of cytokines may help further the understanding of the mechanisms involved in endotoxin-sensitised $\mathrm{HI}$ brain injury and provide possible therapeutic options to minimise injury to the developing nervous system.

Published: 9 July 2012

doi:10.1186/1753-6561-6-S4-09

Cite this article as: Sahota et al:: TNF gene deletion prevents

lipopolysaccharide-mediated sensitisation of the neonatal mouse brain to hypoxic-ischaemic insult. BMC Proceedings 2012 6(Suppl 4):O9. 